\title{
MEASURES OF QUALITY IN ONLINE EDUCATION: AN INVESTIGATION OF THE COMMUNITY OF INQUIRY MODEL AND THE NET GENERATION*
}

\author{
PETER SHEA, PH.D. \\ State University of New York at Albany \\ TEMI BIDJERANO, PH.D. \\ Furman University
}

\begin{abstract}
The goal of this article is to present and validate an instrument that reflects the Community of Inquiry Model (Garrison, Anderson, \& Archer, 2000, 2001) and inquire into whether the instrument and the model it reflects explain variation in levels of student learning and satisfaction with online courses in a higher education context. Additionally this study sought to examine the effects of two other variables - age and students' registration status - on levels of satisfaction and learning in online courses. The issue of age and the "net generation" has generated considerable interest recently with a number of contradictory predictions made for younger students engaged in text-based, technology-mediated learning environments. Previous research indicates that student registration status serves as a relatively reliable predictor of commitment to degree and likely persistence in higher education (Horn \& Neville, 2006) - does commitment to degree predict satisfaction and likely persistence with online learning in the same manner? We sought to inquire into the amount of variance these variables predict relative to constructs in the Community of Inquiry Framework. Results indicated that the instrument provides a coherent factor structure that reflects the Community of Inquiry Model. Other findings provide new insight into additional variables that account for variation in students' satisfaction, reported learning, and cognitive presence in text-based, asynchronous online environments.
\end{abstract}

*This research was supported in part by the SUNY Learning Network, Office of the Provost, State University of New York at Albany.

(c) 2008, Baywood Publishing Co., Inc.

doi: 10.2190/EC.39.4.b

http://baywood.com 
The Community of Inquiry Model (Garrison et al., 2000, 2001) is one of the few theoretical frameworks that attempts to systematically describe and explain the underlying processes and dynamics of student engagement and learning in online environments. Rooted in the literature reflecting a Dewian perspective (Dewey, 1897, 1910) that highlights critical thinking, the Community of Inquiry Framework represents a departure from a-theoretical "best practice" models. The framework aims to articulate the social and academic factors necessary for the development of high-quality online education. Beginning with the premise that knowledge is constructed through critical inquiry that occurs within focused communities of discourse, the model seeks to identify the elements that contribute to the development of authentic collaboration and online learning. To achieve this goal, the authors examined online course transcripts and identify various forms of "presence" which may exist in virtual educational environments. The three forms have been defined as teaching presence, social presence, and cognitive presence. These three forms of presence, described in detail below, combine to contribute to an online community, the goal of which is the construction of new knowledge and learning through individual and joint, collaborative activity. In previous work in this area we sought to investigate components of this model, teaching presence and the development of community specifically (Shea, $\mathrm{Li}, \&$ Pickett, 2006; Shea, Li, Swan, \& Pickett 2005; Shea, Pickett, \& Pelz, 2003). The goal of this article is to present and validate an instrument that reflects the entire Community of Inquiry Model and inquire into whether the instrument and the model it reflects explain variation in levels of student learning and satisfaction with online courses in a higher education context. Additionally we sought to examine the effects of two other variables - age and students' registration status - on levels of satisfaction and learning in online courses. The issue of age and the "net generation" has generated considerable interest recently with a number of contradictory predictions made for younger students engaged in technology-mediated learning environments. This article seeks to empirically investigate some of these open questions. Others working in this area suggest that such research is much needed to advance the field of online teaching and learning (Garrison \& Arbaugh, 2007). As the next section documents, issues surrounding student learning in online environments are of increasing importance as the extent of online instruction in the United States continues to expand rapidly.

In the last decade distance education has been increasingly employed as a means through which students can meet the often competing demands of school, family, and work. For example, approximately $56 \%$ of all 2- and 4-year higher education institutions offered distance learning opportunities in 2001 (U.S. Department of Education, National Center for Education Statistics, 2003). Among public institutions that number is far higher, with roughly $90 \%$ of all public colleges offering at least some distance learning courses in 2001. Most of these courses are now offered over the internet- $90 \%$ of colleges providing distance education reported that they offered asynchronous internet-based courses (U.S. 
Department of Education, National Center for Education Statistics, 2003). It is estimated that 3.2 million students were enrolled in such courses in the United States in 2005 (Allen \& Seaman, 2006) and that more than 4 million were enrolled in fall 2008 (Theil, 2008). Further, it is estimated that growth in enrollments in online higher education will continue to represent the majority of distance education offerings, with growth rates about ten times that of traditional, classroom-based higher education. Online education is now also expanding into the lives of pre-college learners with an estimated 700,000 students enrolled in one or more courses at the K-12 levels (Picciano \& Seaman, 2007). Clearly it is crucial that we gain a better understanding of the conceptual and practical issues that frame the quality of the learning experience in these rapidly growing and changing environments. The issue of the appropriateness of online education for younger students is particularly significant given the recent and rapid growth in this sector. The Community of Inquiry (CoI) Model represents a promising framework for providing such insight. What follows is a more detailed description of the components of the model.

\section{TEACHING PRESENCE}

Garrison, Anderson, and Archer (2001) define teaching presence as the design, facilitation, and direction of cognitive and social processes for the realization of personally meaningful and educationally worthwhile learning outcomes. In the model, teaching presence has three components: instructional design and organization, facilitating discourse, and direct instruction. These categories align well with others identified by researchers working on the roles of instructors in online environments (e.g., Berge, 1995). Under the category instructional design and organization, the authors include setting curriculum, designing methods, establishing time parameters, utilizing the medium effectively, and establishing "netiquette."

The second component of teaching presence in the Community of Inquiry model is facilitating productive discourse. The task of facilitating discourse is necessary to maintain learner engagement and refers to focused and sustained deliberation that marks learning in a community of inquiry (Garrison et al., 2001). The authors provide indicators of the activity of facilitating discourse, which include: identifying areas of learner agreement and disagreement; seeking to reach consensus and understanding; encouraging, acknowledging, and reinforcing student contributions; setting the climate for learning; drawing in participants and prompting discussion; and assessing the efficacy of the process.

Garrison et al. (2001) also include indicators of direct instruction in their framework for the analysis of teaching presence. These indicators include presenting content and questions, focusing and summarizing discussion, confirming understanding, diagnosing misperceptions, injecting knowledge from diverse sources, and responding to technical concerns. 
The nascent literature on teaching presence indicates that the construct coheres as an interpretable factor (Arbaugh \& Wang, 2006; Shea et al., 2006) and that instructor skills in this area are strongly correlated with online learners' sense of community (Shea et al., 2005; Wilson, Ludwig-Hardman, Thornam, $\&$ Dunlap, 2004), satisfaction, and learning (Shea et al., 2005, 2006). In a 5-year case study, Kamin et al. (2006) concluded that the instructor's teaching presence behaviors varied as experience with new content was gained. The authors concluded that the instructor initially generated excessive numbers of messages as she grappled with new content and courses, achieving appropriate levels with time. Other research (Shea et al., 2003) suggests that teaching presence skills can be taught and that online faculty who receive this training improve more quickly than in Kamin's study. This research also indicates that student ratings of trained instructors and their courses are more positive than those of instructors who do not receive teaching presence training (Shea, 2003). This is significant given that other work in this area has concluded that appropriate levels of teaching presence supports cognitive presence, a multivariate indicator of learning evident in online discourse, regardless of whether the discourse was text-based synchronous (Stein, Wanstreet, Glazer, Engle, Harris, Johnston, et al., 2007), textbased asynchronous (Vaughan \& Garrison, 2005), or asynchronous with audio feedback (Ice et al., 2007a, 2007b).

\section{SOCIAL PRESENCE}

The literature on social presence is a great deal more detailed than either teaching presence or cognitive presence in light of its longer history, starting in communications research. Social presence is a construct originally proposed by Short, Williams, and Christie (1976) in their early research on the effectiveness of various media for communications, largely in business environments. They initially characterized social presence as a subjective quality of a particular medium. The authors define social presence as "the degree of salience of the other person in the interaction and the consequent salience of the interpersonal relationship" (Short et al., 1976). In this model of social presence, media are considered to have inherent capacities to carry and transmit social presence; those best able to mimic face-to-face interaction are considered to have the highest degree of social presence. According to this view, the less information that a medium is capable of transmitting, such as information about facial expressions and gestures, the lower the medium's social presence ranking relative to others. The authors provided support for this hypothesis using a variety of media and communicative tasks. Additional research in this area supported some of these conclusions - for example Walther and Parks (2002) reviewed literature indicating that text-based communication more frequently resulted in a "task orientation," and an absence of clear group leadership and consensus, especially around affective topics. Culnan and Markus (1987) refer to these deficit approaches as 
the "cues filtered out" model suggesting that the absence of body language and social context information which signal rules of decorum, roles, status, and affect result in more frequent hostility and higher degrees of task orientation among computer-mediated communicators. Online teaching and learning conducted in asynchronous environments would thus not be expected to result in high levels of social presence nor in productive communities of learners.

Subsequent research, however, suggests that more complex mechanisms predict social presence, accompanying levels of satisfaction, and the effectiveness of computer mediated communication for learning. For example media richness theory (Daft, Lengel, \& Trevino, 1987) posits that there is a best match between the ambiguity of communication tasks and the media one chooses with which to communicate. More ambiguous messages, it is suggested, are most effectively communicated in richer media (e.g., video-conferencing). Messages that are less uncertain are not affected by the richness of the medium of communication but are more efficiently communicated in leaner media (e.g., text-based media). Results of research on media richness theory have been inconsistent-when subjects are asked to choose various media for the accomplishment of tasks of varying levels of equivocality, there appears to be confirmation for hypotheses the theory generates. Other research approaches (experimental and observational) indicate that lean media are often used quite effectively for the accomplishment of very ambiguous communicative tasks (Dennis \& Kinney, 1998; Fulk, Schmitz, \& Steinfeld, 1990; Markus, 1994). Wise, Chang, and Duffy (2004) found that social presence did not contribute to learners' satisfaction, reported learning, or final course product grades, but that social presence affects the learner's interactions and perception of the instructor. Their findings suggest social presence is a correlational rather than a causal variable associated with student learning. Cleary, these vary basic communicative issues are of great importance when considering the potential of online environments to support learning.

What is lacking from much of this analysis of social presence in higher education contexts is a focus on the underlying social and cognitive processes that support learning, rather than the nature of the technologies deployed. The Community of Inquiry model focuses on these processes and articulates social presence not as a function of the medium of delivery but through the capacity of participants to establish satisfying relationships and levels of interaction necessary to engage in discourse that is foundational to learning. Garrison et al. (2000) define social presence as: "the ability of participants in the Community of Inquiry to project their personal characteristics into the community, thereby presenting themselves to the other participants as "real people." A good deal of research suggests that the absence of face-to-face interaction in online learning is likely to cause miscommunication and misunderstanding (see e.g., Clark \& Krych, 2004; Kraut, Gergle, \& Fussell, 2002 on problems related to "grounding"). The notion of social presence is an inclusive construct meant to help identify, address, 
and resolve the kinds of miscommunications that may impede learning. A small number of promising research studies using the social presence construct have been completed (Richardson \& Swan, 2003; Swan \& Shih, 2005). In the instrument tested here we extend this line of research using Garrison's description to develop a social presence subscale for an overarching CoI scale.

\section{COGNITIVE PRESENCE}

Cognitive presence is defined as "the extent to which learners are able to construct and confirm meaning through sustained reflection and discourse in a critical community of inquiry" (Garrison et al., 2000, p. 5). The notion of cognitive presence "thus reflects higher-order knowledge acquisition and application and is most associated with the literature and research related to critical thinking" (p. 6). This focus on critical thinking as a foundation for the model is consistent with current conception of the role of higher education vis-à-vis student learning. Much of the emphasis on the importance of critical thinking can be traced back to Dewey (1910) who argued that it should be a central aim of the college experience. The impact of the work of Dewey is reflected in later efforts to reform U.S. higher education, for example the Rockefeller Commission's Report on the Humanities (Commission on the Humanities, 1980). Largely as a result of these efforts, the U.S. Department of Education elected to include critical thinking in its definitions of the goals of higher education, and colleges across the United States have since incorporated it into the curriculum (Ircink-Waite, 1989). At a conceptual level, when looking at learning in higher education online environments it therefore makes sense to frame knowledge development through the lens of critical thinking. The conceptualization of cognitive presence in the Community of Inquiry model is unique in this sense and represents an advance over other approaches that lack such a rich and historically grounded theoretical focus on critical thinking.

\section{THE “NET GENERATION” AND “COMMITMENT TO DEGREE”}

A great deal has been written recently about the mismatch between the dominant pedagogy of schools and the needs of today's "digital natives"younger students who have grown up immersed in new media (e.g., Gee, 2003, 2005; Prensky, 2003, 2005). The claim in this line of writing is that the curriculum and pedagogy of schooling is out of step with the expectations of today's students and that institutions of education at all levels would do well to integrate more recent technologies, such as video games and other visually rich and interactive media, into instruction to "engage" rather than "enrage" younger students (Prensky, 2003). This work suggests that text-based asynchronous online learning networks (ALNs), typical of online higher education, are unlikely 
to satisfy younger students. However, other studies document the rapid growth of such online education among pre-college age students. In 2000-2001, Clark (2001) estimated that 40,000 to 50,000 students were enrolled in ALN online courses. In 2003, Newman, Stein, and Trask, put the number at approximately 300,000 . In 2007, a study by Picciano and Seaman (2007) suggested that more than $700,000 \mathrm{~K}-12$ students were involved in online education. While exact estimates remain elusive, rapid expansion in online education for younger students is well documented and this growth extends through the early college years.

Given this growth, there has been an increase in interest in student age as it impacts performance in online learning environments. Research into the experience of younger online college students is nascent and mixed. While some researchers have found negative effects for younger students relative to their older counterparts in higher education, others have found no effect by age. For example Carbonaro, Dawber, and Arav (2006) studied online college students' performance on examination over time and found that older students outperformed their younger counterparts as they gained more experience in online education. Similarly, Richardson and Newby (2006), studying cognitive engagement in online environments, found negative effects for age in students' uses of learning strategies, with younger students more likely to employ surface strategies and motives in their online learning. Along similar lines, Hoskins and van Hoof (2005) found that older students were more active in online discussion with the number of hits, length of access, and overall use of the bulletin board predicted by age. This is important in that bulletin board use influenced achievement, with those posting more messages outperforming those not using or passively using this online discussion mechanism (i.e., younger students) (Hoskins \& van Hoof, 2005).

Conversely, in a study of nursing students' preference for a hybrid format, Salamonson and Lantz (2005) found no correlation between the age of the student and their satisfaction level with the format. Fletcher (2005) also failed to find significant differences between old and younger students' self-efficacy scores in a study of an intervention for supporting the technological literacy of undergraduate students who were using online course management systems, but a relationship between experience with computers and scores was found. This raises the question as to whether the possibility of younger students' relatively poor performance found in other studies might be an artifact of their experience with computers rather than age per se. A large body of work, however, reports that younger students seem to be quite comfortable with computers, internet use, and technology in general (e.g., Brown, 2002; Oblinger \& Oblinger, 2005).

Given that studies showing no differences by age examined students who were not engaged in fully online courses, the question also remains as to the possible positive impact of hybrid or blended instruction (some classroom learning and some online learning) for younger students. There has been limited empirical work in this specific arena. In one study, Dziuban (2007) examined the experiences of 
students of varying ages in blended learning environments and found that the youngest ("millennials") were least engaged in blended learning and also less likely to find positive effects of enhanced interaction in such courses when compared to older age groups. Shea et al. (2006) also examined age as a construct that impacts online learner satisfaction. In a study of student ratings of instructor teaching presence behaviors they found that online students' perceptions of instructional quality were much more likely to predict variance in levels of satisfaction with online education than was age. Regardless of age, or format (blended or fully online), variance in both satisfaction and reports of learning was accounted for more completely by students' ratings of instructor teaching presence behaviors. It thus appears that many questions surrounding student age in higher-education online and blended environments remain unresolved at this point.

Given the mixed results of studies attempting to understand the importance of age versus the design and facilitation of learning within the online environment, this study seeks to approach this question from both theoretical and empirical perspectives. Employing the Community of Inquiry framework as a basis for designing an instrument to assess the quality of an online learning environment, we will first explore the appropriateness of the item groups as useful factors for describing online students' perceptions of their learning experiences. We will then use students' ratings of online instruction as described by this exploratory $\mathrm{CoI}$ instrument as a predictor of satisfaction and learning and investigate the impact of age while holding these instructional-quality variables constant.

The issue of attrition in higher education has garnered significant attention in recent years with hundreds of articles, a dedicated journal, and annual conferences devoted to the problem. Research on attrition in online education remains in the early stages, but concerns have been raised. At this point it is necessary to borrow from the extensive literature on traditional student departure from college to better understand the issues. Some of the best of this research centers on concepts core to this investigation, including the connection between learner engagement (e.g., Kuh, 2003; Umbach \& Wawrzynski, 2005; Zhao \& Kuh, 2004), learning community (e.g., Tinto, 1997), and student satisfaction, learning, and persistence. Studies of persistence in traditional face-to-face 4-year and community colleges suggest that part-time status, identified as a less efficient pathway to graduation, is associated with higher attrition rates (Bradburn, 2002; Johnson, 2006) and low engagement (Marti, 2008). Previous investigations have analyzed learner "commitment to degree" as a major predictor of persistence in the classroom (Horn \& Neville, 2006). A core component of commitment to degree is reflected in student registration status, with those registered full-time signaling a greater level of commitment than part-time and non-matriculated students (Horn $\&$ Neville, 2006). In this research we use this measure as an independent variable to account for relative variance in satisfaction, learning, and cognitive presence in the online environment studied here. 


\section{RESEARCH QUESTIONS}

1. Do the items used in the instrument to describe teaching, social, and cognitive presence cohere into interpretable factors that reflect the intended latent constructs within the Community of Inquiry (CoI) Framework?

2. Does learner age predict variance in satisfaction with online learning? What percentage of the variance in satisfaction is associated with age as opposed to other constructs such as registration status and ratings of teaching, social, and cognitive presence?

3. Does learner age or registration status predict variance in student perceptions of teaching, social, and cognitive presence? Do younger or part-time students score lower on these variables?

4. Do the hypothesized constructs of teaching and social presence predict variance in learner reports of cognitive presence as would be predicted by the CoI framework? What is the percentage of variance in cognitive presence predicted by teaching and social presence as opposed to other variables such as age and registration status?

\section{METHOD}

\section{Instrument Construction}

The instrument used in this study was developed in collaboration with several other researchers interested in the Community of Inquiry Framework (see acknowledgments below). To develop the overall $\mathrm{CoI}$ instrument, researchers who had developed previous scales and subscales (Arbaugh, 2007; Arbaugh \& Hwang, 2006; Garrison \& Cleveland-Innes, 2005; Garrison, Cleveland-Innes, \& Fung, 2004; Ice, Arbaugh, Diaz, Garrison, Richardson, Shea, \& Swan, 2007; Richardson \& Swan, 2003; Shea, Li, \& Pickett, 2006; Swan, 2003; Swan \& Shih, 2005) collaborated to integrate these validated works into a new, single, coherent instrument. Items were discussed for inclusion or exclusion based on criteria for reflection of the CoI model as well as practical concerns such as overall length, redundancy, and readability. Given that this was one of the first attempts to develop an omnibus $\mathrm{CoI}$ instrument, we considered this research to be somewhat exploratory in nature. A description of the factor analysis results appears below.

\section{Sample}

The original sample used in this study was drawn from students participating in a multi-institutional, asynchronous, primarily text-based, online learning network. A random sample of students was requested to complete the survey when they logged into the online system. This sample has several advantages-it is broad in that it represents dozens of institutions and it is large, with more than 1,100 responses - a figure that is appropriate for factor analytic studies such as this one. The sample also represents learners studying in a program with 
a single course management system, a single faculty development and training program, a single technology infrastructure provider, and a single student and faculty helpdesk. All of the courses are based on a common instructional design template and contain common documents allowing for the description of the course, its goals, objectives, readings, instructor expectations, learning activities, evaluation criteria, schedule, etc. The courses also all have a similar modular structure with common components allowing for module level description, goals, due dates, and learning activities. The sample thus avoids many pitfalls associated with multi-institutional analysis in which learning environment differences in technology, instructional design, support, or training are uncontrolled variables themselves. Finally, the 39 public institutions in this higher education virtual learning environment are quite diverse, representing community colleges, 4-year liberal arts colleges, and university centers offering degrees from one large, public state university system.

The initial sample contained 1,555 responses from students enrolled in fully online college courses in the college system that was the focus of the study. In the sample, $12.2 \%$ (189 cases) had missing values on any of the 34 variables under consideration. These 189 cases were excluded from the data set. The variables were examined for skewness and kurtosis to determine their univariate normality. The maximum absolute value for skewness was 1.79 and that for kurtosis was 3.11. The first four items from the set (questions 22, 23, 24, and 25) had somewhat pronounced negative skew and positive kurtosis. Nevertheless, the skewness and kurtosis of these four variables was judged as being within acceptable ranges, according to the interpretative guidelines set forth by Tabachnick and Fidell (2001).

The remaining 1,366 cases were examined for univariate outliers. Univariate outliers were sought by examining the $z$ scores for each of the 34 variables. Table 1 displays the number and percent of univariate outliers (with $z>|3.26|$ ) for each of the variables.

All cases with extreme high or low scores on any of the variables were deleted from the analysis: 1,265 cases remained. Following the deletion of the outliers, a substantial improvement in the skewness and kurtosis of the variables was noted.

To establish whether the data conforms to the assumption of multivariate normality, a variable of random numbers was created and regressed on the 34 variables. Using the Mahalanobis distance as a criterion (chi-square (34), $p<.001), 159$ cases were identified as multivariate outliers, and the data from these cases were also deleted.

\section{RESULTS}

\section{Exploratory Factor Analysis}

Principal axis factoring with Oblique rotations was performed using data from 1,106 students. The analysis was conducted using SPSS 15 . When the 
MEASURES OF QUALITY IN ONLINE EDUCATION $/ 349$

\begin{tabular}{lcc}
\multicolumn{3}{c}{ Table 1. } \\
\multicolumn{3}{c}{$\begin{array}{l}\text { Univariate Outliers for Each } \\
\text { of the Variables }\end{array}$} \\
\hline Variable & Frequency & Percent \\
\hline 23 & 49 & $3.6 \%$ \\
25 & 43 & $3.1 \%$ \\
38 & 14 & $1.0 \%$ \\
39 & 16 & $1.2 \%$ \\
40 & 17 & $1.2 \%$ \\
41 & 12 & $.9 \%$ \\
42 & 16 & $1.2 \%$ \\
47 & 24 & $1.8 \%$ \\
50 & 26 & $1.9 \%$ \\
52 & 32 & $2.3 \%$ \\
\hline
\end{tabular}

number of factors was set to vary, a four factor structure emerged. All four factors had eigenvalues greater than 1.00 (see Table 2). The results from the screen plot analysis and the parallel analysis confirmed that the number of factors should be four.

The first extracted factor consisted of 12 items and accounted for $57.73 \%$ of the variance. The reliability of the factor was .97. The items, part of the factors, all dealt with the motivating value of the students' online experiences relative to development of new knowledge; hence the factor was labeled "Cognitive Presence."

The second factor was comprised of nine items, accounted for another $7.54 \%$ of the variance, and produced a reliability estimate of .96 . The items in this factor reflected students' comfort with the classroom discussions and representing themselves as individuals; therefore the factor could be termed "Social Presence: Affective Expression, Open Communication, and Group Cohesion."

The third factor was composed of nine items, all of which mirrored the instructors' facility with delivering the course content and managing the virtual classroom. The factor could be labeled "Teaching Presence: Facilitation." It accounted for an additional $5.25 \%$ of the variance and demonstrated an internal consistency of .93 .

The fourth extracted factor had four items and accounted for 3.98\% of the variance. Its estimated reliability was .95 . The items in this factor were all related to activities associated with the design of the online course before delivery and can be tentatively labeled "Teaching Presence: Design and Organization." 
Table 2. Results from Principal Axis Factoring with Oblique Rotations: Factors and Loadings

\begin{tabular}{llllll}
\hline & \multicolumn{4}{c}{ Factors } & h2 \\
\cline { 2 - 4 } Items & F1 & F2 & F3 & F4
\end{tabular}

22. The instructor clearly communicated important course topics.

23. The instructor clearly communicated important $\quad \begin{array}{llllll}\text { 20 } & .66 & .13 & .6 & .66 & .66\end{array}$ course goals.

24. The instructor provided clear instructions on how $\quad \begin{array}{lllll}.00 & .18 & .25 & .65 & .82\end{array}$ to participate in course learning activities.

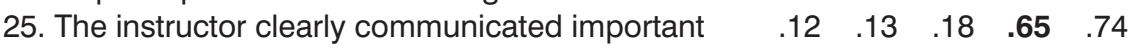
due dates/time frames for learning activities.

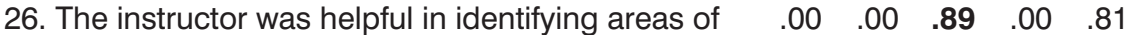
agreement and disagreement on course topics that helped me to learn.

27. The instructor was helpful in guiding the class $\quad \begin{array}{llllll}.00 & .00 & .90 & .01 & .84\end{array}$ toward understanding course topics in a way that helped me clarify my thinking.

$\begin{array}{llllll}\text { 28. The instructor helped to keep course participants } & .01 & .00 & .97 & .00 & .86\end{array}$ engaged and participating in productive dialogue.

29. The instructor helped keep the course partici- \begin{tabular}{llllll}
\hline 00 & .00 & .92 & .00 & .86
\end{tabular} pants on task in a way that helped me to learn.

30. The instructor encouraged course participants to explore new concepts in this course.

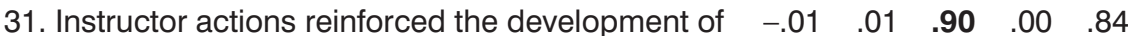
a sense of community among course participants.

32. The instructor helped to focus discussion on relevant issues in a way that helped me to learn.

$\begin{array}{llllll}\text { 33. The instructor provided feedback that helped me } & .21 & .00 & .53 & .53 & .66\end{array}$ understand my strengths and weaknesses relative to the course's goals and objectives.

34. The instructor provided feedback in a timely fashion.

35. Getting to know other course participants gave me a sense of belonging in the course.

36. I was able to form distinct impressions of some of my classmates.

37. Online or web-based communication is an excellent medium for social interaction.

38. I felt comfortable conversing through the online medium.

$\begin{array}{lllll}.16 & .00 & .49 & .32 & .60 \\ .21 & .38 & .33 & -.24 & .57 \\ .23 & .42 & .20 & -.19 & .50 \\ .10 & .50 & .24 & -.19 & .51 \\ .01 & .87 & -.01 & .18 & .77\end{array}$ 
Table 2. (Cont'd.)

\begin{tabular}{llllll}
\hline & \multicolumn{3}{c}{ Factors } & h2 \\
\cline { 2 - 4 } Items & F1 & F2 & F3 & F4
\end{tabular}

39. I felt comfortable participating in the course discussions.

40. I felt comfortable interacting with other course participants.

41. I felt comfortable disagreeing with other course participants while still maintaining a sense of trust.

$\begin{array}{llllll}\text { 42. I felt that my point of view was acknowledged by } & -.01 & .82 & .01 & .00 & .72\end{array}$ other course participants.

43. Online discussions helped me to develop a sense of collaboration with course participants.

44. Problems and issues in this course were interesting to me.

45. Course activities piqued my curiosity.

46. I felt motivated to explore course-related questions.

47. I utilized a variety of information sources to explore problems posed in this course.

48. Brainstorming and finding relevant information helped me resolve issues.

49. Online discussions were valuable in helping me appreciate different perspectives.

50. Combining new information helped me answer questions raised in course activities.

51. Learning activities helped me construct explanations or solutions to course issues or problems.

52. Reflection on course content helped me understand fundamental concepts in this class.

53. I can describe ways to test and apply the knowledge created in this course.

54. I have developed solutions to course problems that can be applied in practice.

55. I can apply the knowledge created in this course to my work or other non-class-related activities.

\begin{tabular}{lrrrr} 
Percent of variance & 57.7 & 7.5 & 5.25 & 3.9 \\
Eigenvalue & 19.8 & 2.8 & 2.03 & 1.5 \\
Reliability & .95 & .96 & .93 & .97 \\
\hline
\end{tabular}

Note: Highest loadings are in bold-face. F1: "Cognitive presence"; F2: "Social presence: Affective expression, open communication, and group cohesion"; F3: "Teaching presence: Facilitation"; F4: "Teaching presence: Design and Organization."

$$
\begin{aligned}
& \begin{array}{lllll}
.00 & .88 & .01 & .19 & .81
\end{array} \\
& \begin{array}{lllll}
.01 & .93 & -.01 & .015 & .83
\end{array} \\
& \begin{array}{lllll}
.00 & .83 & -.01 & .00 & .71
\end{array}
\end{aligned}
$$

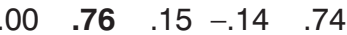

$$
\begin{aligned}
& \begin{array}{lllll}
.86 & .00 & .00 & .00 & .69
\end{array} \\
& \begin{array}{lllll}
.89 & .00 & .00 & .00 & .75
\end{array} \\
& \begin{array}{lllll}
.94 & .00 & .00 & .00 & .79
\end{array} \\
& \begin{array}{lllll}
.83 & -.01 & .01 & .00 & .71
\end{array} \\
& \begin{array}{lllll}
.79 & .00 & .01 & .00 & .71
\end{array} \\
& \begin{array}{lllll}
.43 & .33 & .17 & -.11 & .63
\end{array} \\
& \begin{array}{lllll}
.78 & .11 & .00 & .00 & .76
\end{array} \\
& \begin{array}{lllll}
.82 & .01 & .00 & .01 & .79
\end{array} \\
& \begin{array}{lllll}
.88 & .01 & .00 & .01 & .82
\end{array} \\
& \begin{array}{lllll}
.91 & .00 & .00 & .00 & .78
\end{array} \\
& \begin{array}{lllll}
.89 & .00 & .00 & .00 & .76
\end{array} \\
& \begin{array}{lllll}
.86 & -.01 & .00 & .01 & .73
\end{array} \\
& \begin{array}{llll}
9.8 & 2.8 & 2.03 & 1.5
\end{array} \\
& \begin{array}{llll}
.95 & .96 & .93 & .97
\end{array}
\end{aligned}
$$


It should be noted that only one item showed abnormal loadings. This item was "Getting to know other course participants gave me a sense of belonging in the course." The item was interpreted as belonging to the "Social Presence" factor by virtue of the magnitude of its loading on that factor. The zero-order correlations between each pair of factors are presented in Table 3 .

\section{Multivariate Analysis of Variance: The Effect of Age and Registration Status on the Four Factors}

A two-way multivariate analysis of variance was performed with age, consisting of three categories $(<18$ to 25,26 to 40 , and $>40)$ and registration status (full-time vs. part-time) as independent variables, and the four factors extracted through principal axes factoring as dependent variables. The omnibus MANOVA revealed a significant main effect for age Wilks' lambda $=.97, F(8,2132)=3.80$, $p<.001$; a significant main effect for registration status Wilks' lambda $=.99$, $F(4,1066)=3.11, p=.015$; and no statistically significant interaction effect, Wilks' lambda $=.97, F(8,2132)=.55, p=.81$.

A separate two-way univariate ANOVA with "Cognitive Presence" as dependent variable revealed significant main effects for age $F(2,1075)=6.49, p=.002$, $\eta=.01$. The Scheffe post-hoc test showed that the age group of the 18- to 25 -year-old group reported less cognitive presence $(M=4.10, S D=.69), p<.01$ than the age group of 26 to $40(M=4.24, S D=.67)$ and the students older than $40(M=.4 .30, S D=.62)$. There was no statistically significant differences in the mean scores for the ages 26 to 40 and 41 and older, $p=.51$. Overall, older students tended to report greater cognitive presence in their online courses, regardless of their full-time or part-time registration status. The Levene's test of homogeneity

Table 3. Correlations between the Factors

\begin{tabular}{lcccc}
\hline & $\begin{array}{c}\text { Cognitive } \\
\text { presence }\end{array}$ & $\begin{array}{c}\text { Social } \\
\text { presence }\end{array}$ & $\begin{array}{c}\text { Teaching } \\
\text { presence: } \\
\text { Facilitation }\end{array}$ & $\begin{array}{c}\text { Teaching } \\
\text { presence: } \\
\text { Design and } \\
\text { Organization }\end{array}$ \\
\hline Cognitive presence & - & .68 & .69 & .37 \\
$\begin{array}{l}\text { Social presence } \\
\text { Teaching presence: } \\
\text { Facilitation }\end{array}$ & - & .56 & .19 \\
$\begin{array}{l}\text { Teaching presence: } \\
\text { Design and organization }\end{array}$ & & - & -36 \\
\hline
\end{tabular}


of variance was non-significant, $F(5,1069)=1.01, p=.41$; therefore, the assumption of equality of error variances was met.

An ANOVA with "Social Presence" as dependent variable showed a significant main effect for registration status only $F(1,1075)=4.93, p=.023, \eta=.01$. Regardless of age, full-time online students $(M=4.12, S D=.69)$ scored significantly higher on the social presence factor than the part-time students $(M=4.04$, $S D=.66)$. The assumption for equality of error variances was met, Levene's $F(5,1069)=.96, p=.44$.

The third ANOVA with "Teaching Presence: Facilitation" resulted in nonsignificant effects for age $F(2,1075)=.92, p=.40, \eta=.00$, registration status $F(1,1075)=1.93, p=.17, \eta=.00$, and the interaction term $F(2,1075)=1.83$, $p=.16, \eta=.00$.

In terms of "Teaching Presence: Design and Organization" ANOVA revealed significant main effect for age $F(2,1075)=4.17, p=.016, \eta=.01$. For both types of students (part-time and full-time), the younger students $(<18$ to 25$)$ scored lower on the factor $(M=4.41, S D=.68)$ than the other two groups of students: 26 to 40 years old $(M=4.55, S D=.63), p=.02$ and more than 41 years old $(M=4.56, S D=.64), p=.02$. There was no difference in the scores on the factor for the two older age groups, $p=.97$. The Levene's test of equality of error variances was non-significant, Levene's $F(5,1069)=1.35, p=.24$.

\section{Hierarchical Linear Regression with Overall Course Satisfaction as a Dependent Variable}

A hierarchical multiple regression was employed to determine which of the four factors has significant effect on student overall satisfaction with the course controlling for their registration status and age. The analysis was performed with SPSS REGRESSION.

Table 4 displays the results from the two-step hierarchical regression analysis: correlations between the variables, the unstandardized regression coefficients and intercepts, the standardized regression coefficients, the semipartial correlations and $R, R^{2}$ after all independent variables have been entered into the regression equation. $R^{2}$ was significantly different from zero at the end of each step.

After step 1, with registration status and age in the equation, $R^{2}=.02, F(2,970)$ $=8.02, p<.001$. As seen in Table 4, the regression coefficient for age was statistically different from zero; that is, older students reported greater satisfaction with the courses. When the fours factors-F1: "Cognitive Presence"; F2: "Social Presence"; F3: "Teaching Presence: Facilitation"; and F4: "Teaching Presence: Design and Organization"-were added to the prediction (step 2), $R^{2}=.60$, $F(6,970)=239.78, p<.001$. Of the four factors, only F2: "Social Presence" did not contribute unique variance to the prediction of satisfaction. The results of the analysis indicate that students scoring higher on the dimensions of "Cognitive Presence," "Teaching Presence: Facilitation," and "Teaching Presence: Design 
Table 4. Results From Hierarchical Regression Analysis with Overall Satisfaction Regressed on Registration Status, Age, Cognitive Presence, Social Presence, Teaching Presence: Facilitation and Teaching Presence: Design and Organization

\begin{tabular}{|c|c|c|c|c|c|c|}
\hline \multirow[b]{2}{*}{ Variables } & \multicolumn{3}{|c|}{ Step 1} & \multicolumn{3}{|c|}{ Step 2} \\
\hline & $B(S D)$ & $\beta$ & $s r^{2}$ & $B(S E)$ & $\beta$ & $s r^{2}$ \\
\hline Registration status & $.07 \quad(.05)$ & .04 & & $.09 *(.03)$ & $.06^{*}$ & \\
\hline Age & $.10 *(.03)$ & $.11^{\star}$ & .02 & $.01 \quad(.02)$ & .01 & \\
\hline Cognitive presence & & & & $.29^{*}(.04)$ & $.27^{\star}$ & \\
\hline Social presence & & & & $.01 *(.04)$ & .01 & \\
\hline $\begin{array}{l}\text { Teaching presence: } \\
\text { Facilitation }\end{array}$ & & & & $.13^{\star}(.03)$ & $.15^{\star}$ & \\
\hline \multirow{2}{*}{$\begin{array}{l}\text { Teaching presence: } \\
\text { Design and organization }\end{array}$} & & & & $.48 *(.04)$ & $.43^{*}$ & $.58 *$ \\
\hline & \multicolumn{6}{|c|}{$R=.77, R^{2}=60^{\star}, R^{2}$ adjusted $.60 *$} \\
\hline
\end{tabular}

Note: $N=971,{ }^{\star} p<.001$

and Organization" also tended to report more overall satisfaction, regardless of their registration status and age.

At step two, a substantial reduction in the magnitude of the unstandardized regression coefficient for age was observed, suggesting that the four factors completely mediated the effect of age on overall satisfaction (see Table 4). At the same time, the effect of registration status was reversed; the regression coefficient for registration status became significant.

\section{Hierarchical Linear Regression with Cognitive Presence as a Dependent Variable}

Hierarchal linear regression with "Cognitive Presence" as a dependent variable was performed to examine the unique contribution of the three factors over and above status characteristics such as age and registration status (full-time vs. part-time students).

Similarly to the previous analysis, registration status and age were entered at step one. Both variables explained $2 \%$ of the variance in Student Learning, $R^{2}=.02, F(2,971)=14.09, p<.001$. As shown in Table 5, the regression coefficient for age was statistically significant.

At step 2 with the three factors in the equation, $R^{2}=.70, F(5,971)=615.60$, $p<.001$. The regression coefficient for age remained significant and those 
Table 5. Results From Hierarchical Regression Analysis with Cognitive Presence Regressed on Registration Status, Age, Social Presence, Teaching Presence: Facilitation and Teaching Presence: Design and Organization

\begin{tabular}{|c|c|c|c|c|c|c|}
\hline \multirow[b]{2}{*}{ Variables } & \multicolumn{3}{|c|}{ Step 1} & \multicolumn{3}{|c|}{ Step 2} \\
\hline & $B(S D)$ & $\beta$ & $s r^{2}$ & $B(S E)$ & $\beta$ & $s r^{2}$ \\
\hline Registration status & $.01 \quad(.05)$ & .00 & & $.08 *(.03)$ & $.05^{\star}$ & \\
\hline Age & $.05^{*}(.01)$ & $.14^{\star}$ & .02 & $.03 *(.01)$ & $.09^{*}$ & \\
\hline Social presence & & & & $.42 *(.02)$ & $.40^{\star}$ & \\
\hline $\begin{array}{l}\text { Teaching presence: } \\
\text { Facilitation }\end{array}$ & & & & $.31 *(.02)$ & $.36^{\star}$ & \\
\hline \multirow{2}{*}{$\begin{array}{l}\text { Teaching presence: } \\
\text { Design and organization }\end{array}$} & & & & $.17^{\star}(.02)$ & $.19^{\star}$ & $.68^{*}$ \\
\hline & \multicolumn{6}{|c|}{$R=.84, R^{2}=60^{\star}, R^{2}$ adjusted $.70^{\star}$} \\
\hline
\end{tabular}

Note: $N=972,{ }^{*} p<.001$

of registration status, "Social Presence," "Teaching Presence: Facilitation," and "Teaching Presence: Design and Organization" uniquely contributed to the prediction of learning in their own right.

The results suggest that older students, full-time students, and students with higher scores on the three dimensions of "Social Presence," "Teaching Presence: Facilitation," and "Teaching Presence: Design and Organization" tend also to report cognitive presence to a greater extent, irrespective of the other variables in the model.

\section{DISCUSSION}

In general, these results suggest that items in the instrument developed for this study cohered into interpretable factors that can be understood to reflect the subscales and an overall scale for the Community of Inquiry framework. The analysis resulted in loadings and measures of reliability suggesting the items reflected coherent factors indicative of social presence, cognitive presence, and two "forms" of teaching presence-instructional design and organization and directed facilitation. This dual factor for teaching presence is also consistent with previous research in this area (Shea et al., 2005, 2006) lending evidence to the position that the Community of Inquiry Model might better be conceived as consisting of elements of teaching presence that occur before the inception of 
the course (Instructional Design and Organization) and those that occur during the course (Directed Facilitation).

The analysis of age is interesting in that it provides some evidence for the position that younger students may experience online learning in ways that vary from that of older students. The MANOVA suggests that age and registration status impacts students' perceptions of presence in online courses. In general, students in the youngest age group (18-25) scored lower on one of the measures of teaching presence - instructional design and organization - than did students in older age groups. Both older age groups also reported greater cognitive presence, regardless of their full-time or part-time registration status. The youngest students report the least cognitive presence. Recall that cognitive presence is meant to reflect the extent to which learners are able to construct and confirm meaning through sustained reflection and discourse in a critical community of inquiry. Given the importance of this construct for learning, the result suggesting that younger online students report lower levels of cognitive presence might seen as troubling. However, additional analysis suggests that other factors appear to impact variance in cognitive presence more powerfully. Results from the multiple regression analysis indicate that, while age appears to impact learner perceptions to a small degree, other factors are more important in accounting for variance in students' reports of cognitive presence in their online education. The results of the analysis show that students scoring higher on the dimensions of cognitive presence and the two teaching presence factors also tended to report more overall satisfaction, regardless of their registration status and age. When age and registration status are held constant and student ratings of the Community of Inquiry factors are added to the regression equation, a substantial reduction in the magnitude of the unstandardized regression coefficient for age is observed, suggesting that the four $\mathrm{CoI}$ factors completely mediate the effect of age on overall satisfaction. These results are significant in that they support the position that age is less important to both satisfaction in asynchronous online education than is the orchestration of the learning environment such that high degrees of teaching, social, and cognitive presence (i.e., a productive community of inquiry) is developed. This orchestration is, to a large extent, under the control of the course instructor and, when done well, the community of learners participating in the class. With regard to cognitive presence, however, although experience with online courses were not measured directly in this study, the findings suggest that age and more exposure to online environments may lead to a greater ability to integrate course materials, experiences, and interaction with others into an effective whole. Further research could address the joint effect of age and experience with online learning as potential factors contributing to students' cognitive engagement.

The analysis of registration status and social presence is also interesting. Regardless of students' age, full-time students report a higher level of social 
presence than do part-time students. Recall that the Community of Inquiry model represents social presence as the capacity of participants to establish satisfying relationships and levels of interaction necessary to engage in discourse that is foundational to learning (i.e., the ability of learners to project their personal characteristics into the community, thereby presenting themselves to the other participants as "real people." This finding has a high degree of face validity, as one might expect that students who are engaged in full-time study would be more interested and possibly more able to expend the time and effort necessary to establish a stronger sense of social presence. The concern is that part-time students may be less able to establish the sense of connectedness with online classmates that can lead to sustained and serious discourse and reflection needed to construct knowledge through critical inquiry. Further research is needed to investigate this possibility. However, results presented here raise perhaps even deeper questions as to the importance of social presence for the kinds of activities that were undertaken in the online learning environment investigated here. Social presence was not a significant contributor to the regression analysis predicting students' overall satisfaction. The results therefore open a discussion regarding the role of social presence in asynchronous online higher education. One might wonder whether the task orientation that frequently typifies online asynchronous learning networks reduces the need for a high degree of social presence. Or perhaps the lack of ambiguity in well designed online courses makes social presence less important. The result indicating the relative importance of instructional design and organization to the prediction of online satisfaction and learning suggests the latter of these two speculations may be the more likely. A third interpretation is also possible; i.e., the entire construct of social presence derived from communication research of Short, Williams, and Christie (1976) needs further re-conceptualization for research on online learning. Such a reframing might recognize the significance of "dialogicality" to human consciousness (Bakhtin, 1981) and therefore learning. James Wertsch (2002) touches on this in discussing how new meditational tools, such as threaded discussion forums inherent in text-based online education, shape the forms of dialogue that are privileged in asynchronous learning environments. Wertsch points out, for example, that the kinds of exchange favored in online threaded discussion differ from the "give and take of intense, rapid fire face-to-face interaction where utterances are often fragmentary and interrupted" (Wertsch, 2002, p. 107). Online asynchronous discourse appears characterized instead by "extended, maximally explicit, fully developed and uninterrupted utterances" (Wertsch, 2002, p. 108). This dialogical shift has potentially profound consequences for the expression of social presence in computer-mediated interaction, and this is just one example. Clearly, additional theoretical approaches, further research and a variety of research methods are needed to better understand these changes, the significance and development of social presence, and its impacts on learning in online education. 


\section{REFERENCES}

Allen, E. I., \& Seaman, J. (2006). Growing by degrees: Online education in the United States. Needham, MA: Sloan Center for Online Learning in Education (SCOLE).

Arbaugh, J. B. (2007). An empirical verification of the community of inquiry framework. Journal of Asynchronous Learning Networks, 11(1), 73-86.

Arbaugh, J. B., \& Hwang, A. (2006). Does "teaching presence" exist in online MBA courses? The Internet and Higher Education, 9(1), 9-21.

Bakhtin, M. M. (1981). The dialogic imagination: Four essays by M. M. Bakhtin. M. Holquist (Ed.), C. Emerson \& M. Holquist (Trans.). Austin: University of Texas Press.

Berge, S. L. (1995). Facilitating computer conferencing: Recommendations from the field. Educational Technology, 15(1), 22-30.

Brown, J. S. (2002). Growing up digital. United States Distance Learning Journal, 16(2), $15-28$.

Bradburn, E. M. (2002). Short-Term Enrollment in Postsecondary Education (NCES 2003-153), U.S. Department of Education, Washington, DC.

Carbonaro, M., Dawber, T., \& Arav, I. (2006). A comparison of students' performance under full-time, part-time, and online conditions in an undergraduate nursing microbiology course. Journal of Distance Education, 21(1), 51-61.

Clark, T. (2001). Virtual schools: Status and trends. Phoenix, AZ: WestEd. Retrieved 9/20/2007 from http://www.wested.org/online_pubs/virtualschools.pdf

Clark, H. H., \& Krych, M. A. (2004). Speaking while monitoring addressees for understanding. Journal of Memory and Language , 50(1), 62-81.

Commission on the Humanities. (1980). The humanities in American life: Report of the Commission on the Humanities. Berkeley, CA: University of California Press.

Culnan, M. J., \& Markus, M. L. (1987). Information technologies. In F. M. Jablin (Ed.), Handbook of organizational communication, (pp. 420-443). Newbury Park, CA: Sage.

Daft, R. L., Lengel, R. H., \& Trevino, L. K. (1987). Message equivocality, media selection, and manager performance: Implications for information systems. MIS Quarterly, 11(3), 354-366.

Dennis, A. R., \& Kinney, S. T. (1998). Testing media richness theory in the new media: The effects of cues, feedback and task equivocality. Information Systems Research, 9(3), 256-274.

Dewey, J. (1897). My pedagogic creed. School Journal, 54, 77-80.

Dewey, J. (1910). How we think. Boston : D. C. Heath and Co.

Dziuban, C., Moskal, P., \& Futch, L. (2007). Reactive behavior, ambivalence, and the generations: Emerging patterns in student evaluation of blended learning. In A. G. Picciano \& C. D. Dziuban (Eds.), Blended learning: Research perspectives (pp. 179-202). Needham, MA: Sloan Center for Online Education.

Fletcher, K. (2005). Self-efficacy as an evaluation measure for programs in support of online learning literacies for undergraduates. Internet \& Higher Education, 8(4), 307-322.

Fulk, J., Schmitz, J., \& Steinfield, C. W. (1990). A social influence model of technology use. In J. Fulk \& C. Steinfield (Eds.), Organizations and communication technology. Newbury Park, CA: Sage.

Garrison, D. R., Anderson, T., \& Archer, W. (2000). Critical inquiry in a text-based environment: Computer conferencing in higher education. The Internet and Higher Education, 2(2-3), 1-19. 
Garrison, D. R., Anderson, T., \& Archer, W. (2001). Critical thinking, cognitive presence, and computer conferencing in distance education. The American Journal of Distance Education, 15(1), 7-23.

Garrison, R., \& Arbaugh B. (2007). Researching the community of inquiry framework: Review, issues, and future directions. Internet and Higher Education, 10, 157-172.

Garrison, D. R., \& Cleveland-Innes, M., (2005). Facilitating cognitive presence in online learning: Interaction is not enough. American Journal of Distance Education, 19(3), 133-148.

Garrison, D. R., Cleveland-Innes, M., \& Fung, T. (2004). Student role adjustment in online communities of inquiry: Model and instrument validation. Journal of Asynchronous Learning Networks, 8(2): 61-74.

Gee, J. P. (2003). What video games have to teach us about learning and literacy. New York: Palgrave Macmillan.

Gee, J. P. (2005). Why video games are good for your soul. Australia: Common Ground Publishing.

Horn, L., \& Nevill, S. (2006). Profile of Undergraduates in U.S. Postsecondary Education Institutions: 2003-04: With a Special Analysis of Community College Students (NCES 2006-184). U.S. Department of Education. Washington, DC: National Center for Education Statistics.

Hoskins, S., \& van Hoof, J. (2005). Motivation and ability: Which students use online learning and what influence does it have on their achievement? British Journal of Educational Technology, 36(2), 177-192.

Ice, P., Arbaugh, J., Diaz, S., Garrison, R., Richardson, J., Shea, P., et al. (2007a). Community of Inquiry Framework: Validation and Instrument Development. Paper presented at the 13th Annual Sloan-C International Conference on Online Learning, Orlando, FL.

Ice, P., Curtis, R., Phillips, P., \& Wells, J. (2007b). Using asynchronous audio feedback to enhance teaching presence and student sense of community. Journal of Asynchronous Learning Networks, 11(2), 3-25.

Ircink-Waite, R. M. (1989). A measurement of critical thinking in senior baccalaureate nursing students. Dissertation Abstracts International, 50(11), 3464A.

Johnson, I. Y. (2006). Analysis of dropout behavior at a public research university: The multi-spell discrete-time approach. Research in Higher Education, 47(8), 905-935.

Kamin, C. S.,O’Sullivan, P., Deterding, R. R., Younger, M., \& Wade, T. (2006). A case study of teaching presence in virtual problem-based learning groups. Medical Teacher, 28(5), 425-428.

Kraut, R. E., Gergle, D., \& Fussell, S. R. (2002). The use of visual information in shared visual spaces: Informing the development of virtual co-presence. Proceedings of the 2002 ACM conference on computer supported cooperative work (pp. 31-40). Association for Computing Machinery.

Kuh, G. D. (2003). What we're learning about student engagement from NSSE: Benchmarks for effective educational practices. Change, 35(2), 24-32.

Markus, L. M. (1994). Electronic mail as the medium of managerial choice. Organization Science, 5(4), 502-527.

Marti, C. N. (2008). Latent postsecondary persistence pathways: Educational pathways in American two-year colleges. Research in Higher Education, 49, 317-336. 
Newman, A., Stein, M., \& Trask, E. (2003). What can virtual learning do for your school? Boston, MA: Eduventures.

Oblinger, D., \& Oblinger, J. (2005). Educating the net generation. EDUCAUSE. Downloaded 9/22/07 from http://www.educause.edu/ir/library/pdf/pub7101.pdf

Picciano, A., \& Seaman, J. (2007). K-12 online learning: A survey of U.S. school district administrators. Needham, MA: The Sloan Consortium.

Prensky, M. (2003). e-Nough! "e-Learning" is a misnomer-it's mostly just "e-Teaching." On The Horizon, 11(1), 26-32.

Prensky, M. (2005). Engage me or enrage me: What today's learners demand. EDUCAUSE Review, 40(5), 60-65.

Richardson, J., \& Newby, T. (2006). The Role of students' cognitive engagement in online learning. The American Journal of Distance Education, 20,(1), 23-37.

Richardson, J., \& Swan, K. (2003). Examining social presence in online courses in relation to students' perceived learning and satisfaction. Journal of Asynchronous Learning Networks, 7(1), retrieved from http://www.sloan-c.org/publications/jaln/v7n1/v7n1_richardson.asp

Salamonson Y., \& Lantz, J. (2005). Factors influencing nursing students' preference for a hybrid format delivery in a pathophysiology course. Nurse Education Today, 25(1), 9-16.

Shea, P., Li, C. S., \& Pickett, A. (2006). A study of teaching presence and student sense of learning community in fully online and web-enhanced college courses. The Internet and Higher Education, 9, 175-190.

Shea, P., Li, C. S., Swan, K., \& Pickett, A. (2005). Developing learning community in online asynchronous college courses: The role of teaching presence. The Journal of Asynchronous Learning Networks, 9(4), 59-82.

Shea, P., Pickett, A., \& W. Pelz (2003). A follow-up investigation of teaching presence in the SUNY Learning Network. The Journal of Asynchronous Learning Networks, 7(2), 61-80.

Short, J., Williams, E., \& Christie, B. (1976). The social psychology of telecommunications. New York: Wiley.

Stein, D. S., Wanstreet, C. E., Glazer, H. R., Engle, C. L., Harris, R. A., Johnston, S. M., et al. (2007). Creating shared understanding through chats in a community of inquiry. Internet \& Higher Education, 10(2), 103-115.

Swan, K. (2003). Developing social presence in online discussions. In S. Naidu (Ed.), Learning and teaching with technology: Principles and practices (pp. 147-164). London: Kogan Page.

Swan, K., \& Shih, L. F. (2005). On the nature and development of social presence in online course discussions. Journal of Asynchronous Learning Networks, 9(3), 115-136.

Tabachnick, B., \& Fidell, L. (2001). Using multivariate statistics (4th ed.). Needham Heights, MA: Allyn \& Bacon.

Theil, S. (2008, August 9). Tune in tomorrow: The boom in online education. Newsweek. Retrieved September 5, 2008, from http://www.newsweek.com/id/151688

Tinto, V. (1997). Classrooms as communities-Exploring the educational character of student persistence. Journal of Higher Education, 68(6), 599-623.

U.S. Department of Education, National Center for Education Statistics. (2003). Distance Education at Degree-Granting Postsecondary Institutions: 2000-2001, NCES 2003-017, Washington, DC. 
U.S. Department of Education, National Center for Education Statistics. (2006). The Condition of Education 2006, NCES 2006-071, Washington, DC: U.S. Government Printing Office. U.S. Dept of Education. Retrieved from http://nces.ed.gov/programs/coe/2006/pdf/09_2006.pdf

Umbach, P., \& Wawrzynski, M. (2005). Faculty do matter: The role of college faculty in student learning and engagement. Research in Higher Education, 46, 153-184.

Vaughan, N., \& Garrison, D. R. (2005). Creating cognitive presence in a blended faculty development community. Internet \& Higher Education, 8(1), 1-12.

Walther, J. B., \& Parks, M. R. (2002). Cues filtered out, cues filtered in: Computermediated communication and relationships. In M. L. Knapp \& J. A. Daly (Eds.), Handbook of interpersonal communication. Thousand Oaks, CA: Sage.

Wertsch, J. (2002). Computer mediation, PBL, and dialogicality. Distance Education, 23(1), 105-108.

Wilson, B. G., Ludwig-Hardman, S., Thornam, C. L., \& Dunlap, J. C. (2004). Bounded community: Designing and facilitating learning communities in formal courses. International Review of Research in Open \& Distance Learning; 5(3), 1-19.

Wise, A., Chang, J., \& Duffy, T. (2004). The effects of teacher social presence on student satisfaction, engagement, and learning. Journal of Educational Computing Research, $31(3), 247-271$.

Zhao, C., \& Kuh, G. (2004). Adding value: Learning communities and student engagement. Research in Higher Education, 45, 115-138.

Direct reprint requests to:

Dr. Peter Shea

Assistant Professor of Education

Educational Theory and Practice \& Dept. of Informatics

University at Albany, State University of New York

ED114

1400 Washington Ave.

Albany, NY 12222

e-mail: pshea@uamail.albany.edu 
Copyright of Journal of Educational Computing Research is the property of Baywood Publishing Company. Inc. and its content may not be copied or emailed to multiple sites or posted to a listserv without the copyright holder's express written permission. However, users may print, download, or email articles for individual use. 
Copyright of Journal of Educational Computing Research is the property of Baywood Publishing Company, Inc. and its content may not be copied or emailed to multiple sites or posted to a listserv without the copyright holder's express written permission. However, users may print, download, or email articles for individual use. 